\title{
Reversible Sidewall Osmylation of Individual Carbon Nanotubes
}

\author{
Jingbiao Cui,, Marko Burghard, and Klaus Kern \\ Max-Planck-Institut fuer Festkoerperforschung, Heisenbergstrasse 1, \\ D-70569 Stuttgart, Germany
}

Received March 6, 2003; Revised Manuscript Received March 25, 2003

\begin{abstract}
Sidewall osmylation of individual metallic single-walled carbon nanotubes has been achieved by exposing the tubes to osmium tetroxide vapor under UV photoirradiation. The covalent attachment of the osmium oxide leads to an increase in the electrical resistance by up to several orders of magnitude. The cycloaddition product can be cleaved by UV light in vacuum or under an oxygen atmosphere, whereby the original resistance is restored.
\end{abstract}

Single-walled carbon nanotubes (SWCNTs), with a diameter in the nanometer scale range and a length of several micrometers, represent attractive components for nanoscale electronic devices because of their unique electronic, mechanical, and chemical properties. ${ }^{1}$ Depending on their chirality, SWCNTs are either metallic or semiconducting nanowires. ${ }^{2}$ It is well documented that the electronic properties of SWCNTs are sensitive to the environment, 3,4 which constitutes the basis for using nanotubes in chemical sensors. ${ }^{4-6}$ Recently, considerable effort has been directed toward chemical modification of the nanotube sidewall by attaching organic or inorganic functional groups. ${ }^{6-16}$ Methods for sidewall functionalization include electrochemical attachment of phenyl groups, ${ }^{7 \mathrm{a}, \mathrm{b}}$ decoration with selenium nanoparticles, ${ }^{8}$ covalent attachment of nitrenes, ${ }^{9}$ fluorination, ${ }^{10 a-c, 11 a, b}$ ozonolysis, ${ }^{12 a, b}$ and noncovalent attachment of polymers $^{13,14}$ as well as physical evaporation of metal nanoparticles. ${ }^{15,16}$ Although these achievements extend the range of potential applications of SWCNTs, little is known about changes in their electronic properties induced by the attached functional groups. ${ }^{12,17,18}$ For bulk nanotube samples, both fluorination and ozonolysis have been observed to reduce the conductivity of SWCNTs. ${ }^{10 a, 12 a}$ The interpretation of these results, however, is complicated by the fact that bulk samples consist of a wide variety of tubes differing in diameter and chirality. The conductivity of single nanotubes has until now been studied only with respect to chemical and electric field-induced doping. For instance, Choi et al. found that oxidizing an individual semiconducting SWCNT with noble-metal ions leads to decreased resistance, which was attributed to an increased p-doping of the tube..$^{18} \mathrm{In}$ contrast, the effect of the chemical attachment of functional

\footnotetext{
* Corresponding author. E-mail: jbcui@yahoo.com.
}

Scheme 1. Reaction Scheme Illustrating the Cycloaddition of Osmium Tetroxide $\left(\mathrm{OsO}_{4}\right)$ to the Sidewall of a Single-Walled Carbon Nanotube (SWCNT) Leading to an Osmyl Ester of a Five-Membered Ring Structure ${ }^{a}$

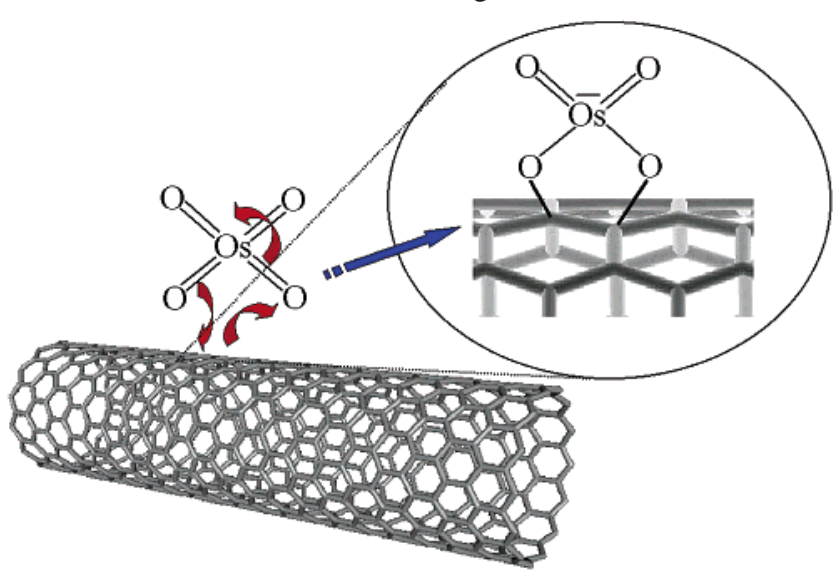

${ }^{a}$ Red arrows indicate the flow of electrons during bond formation.

groups on the electrical properties of single tubes has not yet been investigated.

This communication reports the osmylation of SWCNTs by the cycloaddition of osmium tetroxide $\left(\mathrm{OsO}_{4}\right)$, as schematically depicted in Scheme 1, and its effect on the electrical properties at the single-tube level. Aqueous solutions of $\mathrm{OsO}_{4}$ have been employed to open the ends of nanotubes. ${ }^{19}$ However, recent theoretical calculations indicated that the covalent attachment of $\mathrm{OsO}_{4}$ to the tube sidewall requires catalysis by a base. ${ }^{20}$ This reflects the smaller reactivity of the (defect-free) sidewall region compared to that of the caps containing pentagons. ${ }^{21} \mathrm{We}$ found that sidewall osmylation of SWCNTs can be achieved with $\mathrm{OsO}_{4}$ from the gas phase under photoirradiation in the presence of oxygen. Our in- 


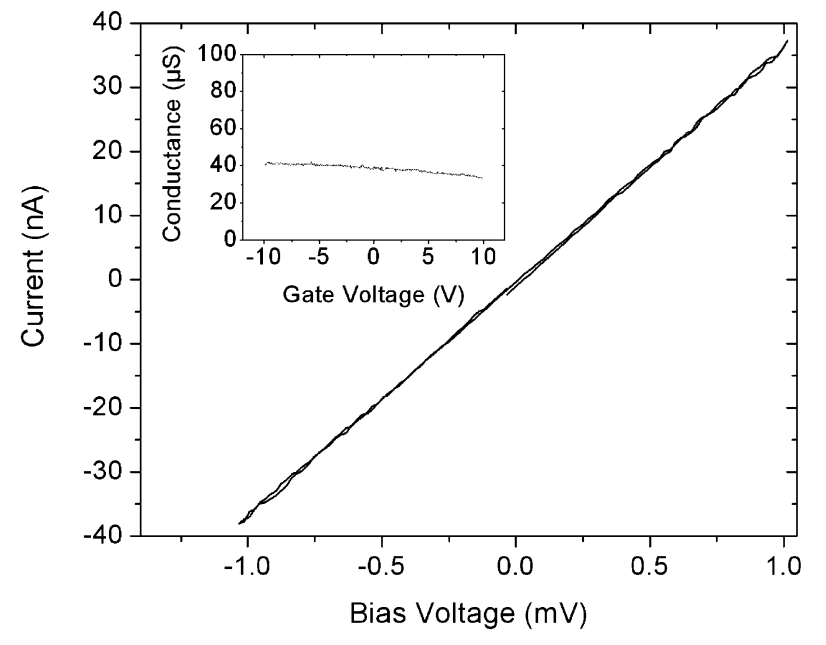

Figure 1. Current/voltage $(I / V)$ characteristic of an individual metallic SWCNT before osmylation showing a two-terminal resistance of $19 \mathrm{k} \Omega$ at room temperature. The tube is contacted with two AuPd electrodes on top ( $\sim 150$-nm electrode separation). The inset displays the tube conductance as a function of gate voltage at room temperature ( $1 \mathrm{mV}$ bias voltage).

situ electrical measurements reveal that the reaction of $\mathrm{OsO}_{4}$ with the sidewall of metallic SWCNTs decreases the tube conductance by up to several orders of magnitude. Photoactivation is also effective for splitting the cycloaddition product into the starting compounds, by which the original resistance of the tube is restored.

SWCNTs were deposited on an $\mathrm{n}^{+}-\mathrm{Si} / \mathrm{SiO}_{2}$ wafer (100$\mathrm{nm}$ oxide thickness) and were contacted by $\mathrm{Au} / \mathrm{Pd}$ electrodes on top ( $\sim 150$-nm electrode separation) as described previously. ${ }^{22}$ The gate dependence of conductance is used to determine whether a given tube is metallic or semiconducting. For the present study, we selected individual metallic SWCNTs characterized by a very small gate dependence, as exemplified in Figure 1 for one specific tube with a roomtemperature resistance of $\sim 19 \mathrm{k} \Omega$. The same tube was placed in a glass chamber that was then evacuated to a pressure of $p=5 \times 10^{-4}$ mbar. After filling the chamber with $\mathrm{OsO}_{4}$ vapor (final concentration $10^{-7} \mathrm{~mol} / \mathrm{cm}^{3}$ ), no resistance change was detected on a time scale of minutes. The addition of pure oxygen, which was tested for pressures up to 0.2 bar, did not change the behavior as shown in region I of Figure 2. An increase in resistance was observed (region II) when the tube in the $\mathrm{OsO}_{4}+\mathrm{O}_{2}$ atmosphere was irradiated through a transparent glass window with UV light $(\lambda=254$ $\mathrm{nm})$. This increase stopped after switching off the UV light source-in the present case, after $50 \mathrm{~min}$ - which resulted in a resistance increase by a factor of 30 . Without UV irradiation, the sample in the $\mathrm{OsO}_{4}+\mathrm{O}_{2}$ atmosphere did not show any further resistance change (region III). After the removal of the $\mathrm{OsO}_{4}$, the original resistance could be recovered by UV irradiation of the tube in the $\mathrm{O}_{2}$ atmosphere (region IV), although this process takes significantly more time than the osmylation. Resistance recovery can also be achieved by irradiation in vacuum; however, this requires longer reaction times than in the $\mathrm{O}_{2}$ atmosphere. Our studies of several different metallic tubes revealed that even after

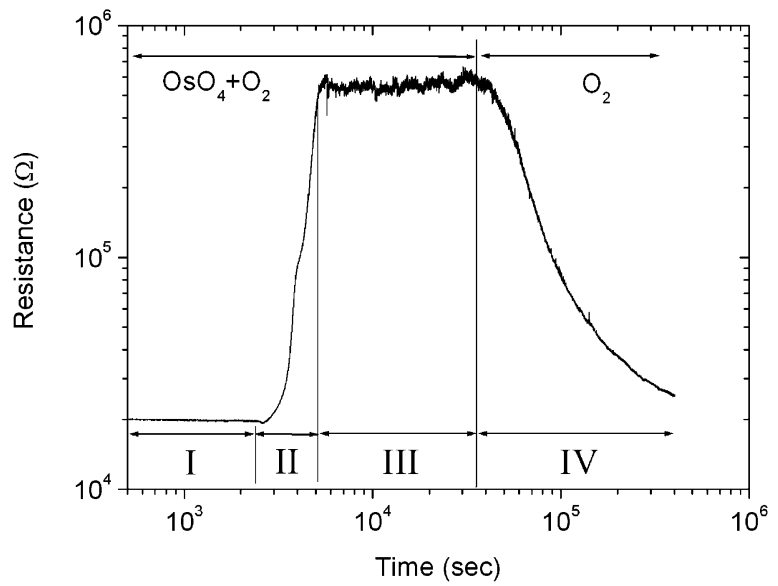

Figure 2. Two-terminal resistance of the metallic SWCNT in Figure 1 measured in situ for different gas-phase compositions. Regions I and II correspond to the tube in the $\mathrm{OsO}_{4}+\mathrm{O}_{2}$ atmosphere without and with UV light irradiation $(\lambda=254 \mathrm{~nm})$, respectively. Within region III, no UV light was used. After the removal of $\mathrm{OsO}_{4}$, the sample was again irradiated with UV light, this time in a pure $\mathrm{O}_{2}$ atmosphere (region IV).

longer osmylation, associated with resistance increases of up to 5 orders of magnitude, the resistance change can be reversed by UV light irradiation. Using the above-described conditions, we found that the resistance of a metallic tube can be cycled at least three times.

We attribute the resistance increase of the metallic SWCNTs to the cycloaddition of $\mathrm{OsO}_{4}$ to the carbon lattice of the tube. Because the adduct formation is associated with transforming carbon/carbon double bonds into carbon/carbon single bonds, it is expected to reduce the $\pi$-electron density and thereby the conductivity of the tube. The formation of covalent bonds between $\mathrm{OsO}_{4}$ and the tube sidewall is supported by the following observations. First, the effect of osmylation could be reproducibly reversed only if the sample remained in the closed chamber during the whole process but not with tubes that had been exposed to ambient conditions after the osmylation. This behavior points to the hydrolysis of the osmyl ester that occurs upon contact with humidity. Second, the fact that without UV irradiation no resistance change is observed indicates that mere physisorption of $\mathrm{OsO}_{4}$ does not affect the carrier density and/or carrier scattering in the metallic tube. It is known that photoexcitation with an energy of least that of the charge-transfer band of arene $/ \mathrm{OsO}_{4}$ complexes leads to the corresponding adducts, ${ }^{23}$ which have, for example, been used in the synthesis of cyclite derivatives from benzene. ${ }^{24}$ It is plausible that a similar reaction takes place with the SWCNTs. Concerning the role of oxygen in the osmylation and reverse reaction, however, we can only speculate at the present stage. As one possibility, oxygen may assist the photoinduced charge transfer between $\mathrm{OsO}_{4}$ and the tube, which represents the rate-limiting step. ${ }^{23}$

In summary, we have shown that osmylation of the SWCNT sidewall can be achieved by photoactivation. Cycloaddition of $\mathrm{OsO}_{4}$ is found to decrease the $\pi$-electron density in the tubes and therefore increases their resistance. Since the cycloaddition can be reversed, this chemical 
modification scheme allows us to tune the electronic properties of single, metallic SWCNTs reversibly at room temperature. More detailed studies of the different modification stages are expected to provide useful insight into the chargetransport characteristics of chemically functionalized tubes. Furthermore, SWCNT osmylation opens the possibility of further well-defined tube modifications such as the introduction of hydroxy groups by the hydrolytic cleavage of the osmyl ester.

Acknowledgment. This work was partially supported by the German BMBF under contract no. 03C0302B.

\section{References}

(1) Hu, J.; Odom, T. W.; Lieber, C. M. Acc. Chem. Res. 1999, 32, 435.

(2) Odom, T. W.; Huang, J. L.; Kim, P.; Lieber, C. M. Nature (London) 1998, 391, 62 .

(3) Zhou, C. W.; Kong, J.; Yenilmez, E.; Dai, H. J. Science (Washington, D.C.) 2000, 290, 1552 .

(4) Collins, P. G.; Bradley, K.; Ishigami, M.; Zettl, A. Science (Washington, D.C.) 2000, 287, 1801.

(5) Kong, J.; Franklin, N. R.; Zhou, C. W.; Chapline, M. G.; Peng, S.; Cho, K. J.; Dai, H. J. Science (Washington, D.C.) 2000, 287, 622.

(6) Kong, J.; Chapline, M. G.; Dai, H. J. Adv. Mater. 2001, 13, 1384.

(7) (a) Bahr, J. L.; Yang, J.; Kosynkin, D.; Bronikowski, M. J.; Smalley, R. E.; Tour, J. M. J. Am. Chem. Soc. 2001, 123, 6536. (b) Kooi, S. E.; Schlecht, U.; Burghard, M.; Kern, K. Angew. Chem., Int. Ed. 2002, 41, 1353.

(8) Fan, Y.; Burghard, M.; Kern, K. Adv. Mater. 2002, 14, 130.

(9) Holzinger, M.; Vostrovsky, O.; Hirsch, A.; Hennrich, F.; Kappes, M.; Weiss, R.; Jellen, F. Angew. Chem., Int. Ed. 2001, 40, 4002.

(10) (a) Mickelson, E. T.; Huffmann, C. B.; Rinzler, A. G.; Smally, R. E.; Hauge, R. H.; Margrave, J. L. Chem. Phys. Lett. 1998, 296, 188. (b) Boul, P. J.; Liu, J.; Mickelson, E. T.; Huffman, C. B.; Ericson, L. M.; Chiang, I. W.; Smith, K. A.; Colbert, D. T.; Hauge, R. H.; Margrave, J. L.; Smalley, R. E. Chem. Phys. Lett. 1999, 310, 367. (c) Kelly, K. F.; Chiang, I. W.; Mickelson, E. T.; Hauge, R. H.; Margrave, J. L.; Wang, X.; Scuseria, G. E.; Radloff, C.; Halas, N. J. Chem. Phys. Lett. 1999, 313, 445. (d) Hayashi, T.; Terrones, M.; Scheu, C.; Kim, Y. A.; Ruhle, M.; Nakajima, T.; Endo, M. Nano Lett. 2002, 2, 491.

(11) (a) Kudin, K. N.; Bettinger, H. F.; Scuseria, G. E. Phys. Rev. B 2001, 63, 5413. (b) Bettinger, H. F.; Kudin, K. N.; Scuseria, G. E. J. Am. Chem. Soc. 2001, 123, 12849 .

(12) (a) Cai, L. T.; Bahr, J. L.; Yao, Y. X.; Tour, J. M. Chem. Mater. 2002, 14, 4235. (b) Lu, X.; Zhang, L. L.; Xu, X.; Wang, N. Q.; Zhang, Q. N. J. Phys. Chem. B 2002, 106, 2136.

(13) Star, A.; Stoddart, J. F.; Steuerman, D.; Diehl, M.; Boukai, A.; Wong, E. W.; Yang, X.; Chung, S. W.; Choi, H.; Heath, J. R. Angew. Chem., Int. Ed. 2001, 40, 1721.

(14) O'Connell, M. J.; Boul, P.; Ericson, L. M.; Huffman, C.; Wang, Y. H.; Haroz, E.; Kuper, C.; Tour, J.; Ausman, K. D.; Smalley, R. E. Chem. Phys. Lett. 2001, 342, 265.

(15) Zhang, Y.; Dai, H. J. Appl. Phys. Lett. 2000, 77, 3015.

(16) Bezryadin, A.; Lau, C. N.; Tinkham, M. Nature (London) 2000, 404, 971.

(17) Amkreutz, M.; Jungnickel, G.; Seifert, G.; Kohler, T.; Frauenheim, T. New Diamond Front. Carbon Technol. 2001, 11, 207.

(18) Choi, H. C.; Shim, M.; Bangsaruntip, S.; Dai, H. J. J. Am. Chem. Soc. 2002, 124, 9058.

(19) Satishkumar, B. C.; Givindaraj, A.; Mofokeng, J.; Subbanna, G. N.; Rao, C. N. R. J. Phys. B 1996, 29, 4925.

(20) Lu, X.; Tian, F.; Feng, Y. B.; Xu, X.; Wang, N. Q.; Zhang, Q. E. Nano Lett. 2002, 2, 1325.

(21) Bahr, J. L.; Tour, J. M. J. Mater. Chem. 2002, 12, 1952.

(22) Cui, J. B.; Burghard, M.; Kern, K. Nano Lett. 2002, 2, 117.

(23) Wallis, J. M.; Kochi, J. K. J. Am. Chem. Soc. 1988, 110, 8207.

(24) Motherwell, W. B.; Williams, A. S. Angew. Chem. 1995, 107, 2207. NL034135P 